\title{
A COLONIALIDADE NAS POLÍTICAS AMBIENTAIS DO GOVERNO BOLSONARO E A INVERSÃO DOS ÓRGÃOS DE DEFESA DO MEIO AMBIENTE
}

\section{COLONIALITY IN ENVIRONMENTAL POLICIES OF BOLSONARO GOVERNMENT AND THE INVERSION OF THE ENVIRONMENTAL DEFENSE INTITUTIONS}

\author{
Leandro Aparecido Fonseca MISSIATTO (EMERON) \\ Leila Gracieli da SILVA (UFSC) ${ }^{2}$ \\ Fábio Rodrigues CARVALHO (UniFacimed) ${ }^{3}$ \\ Daylan Maykiele DENES (UniFacimed) \\ Héverton Magno MISSIATTO (SEDUC-RO) ${ }^{5}$
}

\begin{abstract}
Resumo: O Brasil tem sido destaque no ranking de desmatamento, queimadas, extração de recursos naturais, tráfico de animais e conflitos contra povos originários. As ações governamentais vigentes no país evidenciam que o desmonte das políticas ambientais está calcado na colonialidade com a velha roupagem do progresso a qualquer custo, incluindo um colapso socioambiental, assim, instituições que, em tese, deveriam atuar para proteção do meio ambiente agem sem nenhum tipo de pudor na produção institucional em ofensiva ao meio ambiente. $\mathrm{O}$ presente ensaio discute o que vem acontecendo no cenário institucional brasileiro e quais são os caminhos possíveis através da perspectiva decolonialista e do Bem Viver.
\end{abstract}

Palavras-chaves: Governo Bolsonaro. Meio ambiente. Colonialidade. Decolonialismo.

\begin{abstract}
Brazil has been highlighted in the ranking of deforestation, fires, extraction of natural resources, animal trafficking and conflicts against native peoples. The governmental actions in force in the country show that the dismantling of environmental policies is based on coloniality with the old guise of progress at any cost, including a socio-environmental collapse. Thus, institutions that, in theory, should act to protect the environment, act without any kind of modesty in institutional production in an offensive to the environment. The present essay discusses what has been happening in the Brazilian institutional scenario, and what are the possible paths through the decolonialist and well live perspective.
\end{abstract}

Keywords: Bolsonaro government. Environment. Coloniality. Decolonialism.

\footnotetext{
${ }^{1}$ Doutorando em Psicologia Clínica pela Universidade do Vale do Rio dos Sinos (Unisinos). Docente da Pós-Graduação, lato sensu, em Direito para Carreira da Magistratura da Escola da Magistratura do Estado de Rondônia (Emeron). Docente do curso de Psicologia da Faculdade Estácio de Pimenta Bueno. E-mail: leandro_afonseca@ hotmail.com

${ }^{2}$ Doutoranda em Psicologia pela Universidade Federal de Santa Catarina (UFSC). Possui graduação em psicologia (UNESC/RO); Mestrado em Saúde e Processos Psicossociais pela Universidade Federal de Rondônia (UNIR). E-mail: leila_gracieli@hotmail.com

${ }^{3}$ Acadêmico em Psicologia do Centro Universitário Faculdade de Ciências Biomédicas de Cacoal (UniFacimed). Presidente da Liga Acadêmica Temas Emergentes em Psicologia. Co-desenvolve pesquisas em intolerância religiosa contra religiões de Matriz Africana no interior da Amazônia Ocidental e percepções de estagiários de Psicologia sobre questões étnico-raciais e de classe social em Cacoal/RO. E-mail: fabio.relativity@gmail.com

${ }^{4}$ Acadêmica em Psicologia pelo Centro Universitário Faculdade de Ciências Biomédicas de Cacoal (UniFacimed). Email: dayland44@gmail.com

${ }^{5}$ Mestrando em Educação Profissional e Tecnológica em Rede (ProfEPT). Bacharel em Comunicação Social - Jornalismo pela Universidade Federal de Rondônia (UNIR) Formação em Letras pela Universidade do Norte do Paraná Atua na Ensino Público do Governo do Estado de Rondônia, na Educação Integral. E-mail: professorheverton@ @otmail.com
} 


\section{INTRODUÇÃO}

O ano de 2020 foi campeão em desmatamentos e queimadas dos principais biomas brasileiros (ARAGÃO; SILVA JUNIOR; ANDERSON, 2020). Presenciamos a fauna e flora do país virarem cinzas enquanto o governo federal negava em discursos públicos a existência da crise ambiental que tem avançado a limites irreversíveis $(\mathrm{G} 1,2020)$. O negacionismo do presidente Jair Bolsonaro, e seus ministros, pode ser percebido nos atos oficiais editados pelos principais órgãos de proteção ao meio ambiente cujos conteúdos, essencialmente, atentam contra a segurança da biodiversidade nacional.

$\mathrm{O}$ atual governo além de tacitamente desconsiderar as muitas vulnerabilidades pelas quais historicamente já se encontram suscetíveis os biomas do país, age de modo a ampliar ainda mais as fragilidades de áreas de preservação, desmontando a governança ambiental instituída em 1988 na Constituição Federal e se negando a fazer políticas públicas adequadas para a promoção da defesa do meio ambiente (OBSERVATÓRIO DO CLIMA, 2021). Esse contexto insere o país em um abismal paradoxo: instituições que, em tese, deveriam atuar para proteção do meio ambiente agem sem nenhum tipo de pudor em uma ofensiva institucional contra o meio ambiente, colaborando ativamente para a produção de um desastre global já anunciado (BIODIVERSIDAD LA, 2020). Nesse sentido, o que aflora em termos políticos, é um giro institucional que se manifesta pela conversão dos órgãos de proteção ambiental em verdadeiras máquinas de depredação da biodiversidade brasileira, produzindo, desse modo, uma fratura na lógica de defesa do meio ambiente, em que aqueles que deveriam protegê-lo agem para sua vulnerabilização e ataque.

Considerando a fratura exposta pela ação dos órgãos de defesa do meio ambiente na gestão de Bolsonaro, surgem os seguintes questionamentos: a quem servem as políticas ambientais que se encontram em curso no Brasil? Como tais políticas ambientais estão inscritas na agenda de poder do governo do presidente Bolsonaro? Para responder a esses questionamentos buscamos nas teorias decoloniais recursos teóricos-metodológicos que possibilitem a compreensão do que vem acontecendo no cenário institucional brasileiro e quais caminhos são possíveis.

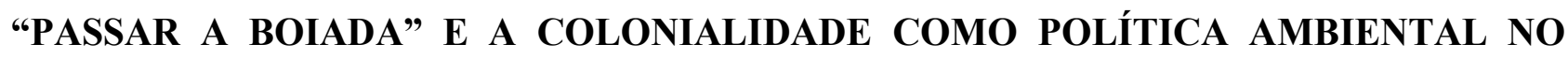 GOVERNO BOLSONARO}

É inegável que se encontra em curso no Brasil uma crise ambiental de grandes proporções. Segundo informações contidas em nota técnica emitida pelo Instituto Nacional de Pesquisas Espaciais (INPE) e pelo Centro Nacional para Monitoramento de Alerta de Desastres Naturais (CEMADEN), 
o desmatamento da Amazônia em um ano (2019/2020) foi 1,7 vezes maior que no período compreendido entre 2016 a 2018 (ARAGÃO; SILVA JUNIOR; ANDERSON, 2020). Além do desmatamento, outro problema comum aos biomas brasileiros são as queimadas. Em 2020, a Amazônia foi o bioma que mais sofreu com queimadas $(46,2 \%)$, seguida pelo cerrado $(31,4 \%)$, pantanal $(11,6 \%)$, mata atlântica $(6,2 \%)$ e caatinga $(4,4 \%)$ (INPE, 2020). No pantanal as queimadas foram $200 \%$ maiores que em 2019, comprometendo cerca de 20\% daquela região (CÂMARA DOS DEPUTADOS, 2020).

Enquanto os ecossistemas nacionais ardem em chamas e são devorados pelo predatismo madeireiro e do agronegócio, o governo federal, por meio de seu maior chefe, o presidente Jair Bolsonaro, junto a sua equipe ministerial, tem postulado um padrão de governança ambiental altamente predatório, colocando em risco a sustentabilidade não apenas do Brasil, mas de todo planeta.

Em reunião ministerial ocorrida em abril de 2020, o então ministro do meio ambiente, Ricardo Salles, chegou a propor uma refundação das políticas ambientais de modo mais incisivo: "Precisa ter um esforço nosso aqui, enquanto estamos neste momento de tranquilidade no aspecto de cobertura de imprensa, porque só se fala de Covid, e ir passando a boiada, e mudando todo o regramento (ambiental), e simplificando normas" (SHALDERS, 2020). Diante desse contexto surge o seguinte questionamento: a mudança de regramento e a simplificação de normas das quais fala Salles estão a serviço de quem?

Para responder esse questionamento precisamos recorrer às epistemologias tipicamente sulamericanas, uma vez que as muitas peculiaridades de nossos territórios nos impedem de que apliquemos com êxito visões globalizadas. Para tanto, tomamos como fundamento o pensamento decolonial proposto pela radicalidade epistemológica dos pensadores e pensadoras da América Latina.

Consideremos alguns elementos basilares a essa discussão: o primeiro diz respeito à colonialidade do poder que se encontra plenamente ativa no Brasil desenvolvendo e gerenciando políticas que se encontram intimamente associadas a nossa experiência colonial; segundo, a política nacional, enquanto expressão verdadeira da colonialidade do poder manifesta-se prioritariamente pela diferença colonial, ou seja, na produção de paralelismo políticos que se mostram plenamente eficientes para a globalização de projetos neoliberais; por fim, como terceiro elemento, a colonialidade não está passível de negociação, ela é autoritária, violenta e intransigente. 
O termo colonialidade foi proposto por Aníbal Quijano e se tornou indispensável para se pensar a modernidade em suas estruturas de poder, saber e ser. O conceito de colonialidade do poder, diz respeito a um dos elementos constitutivos e específicos do padrão mundial do poder capitalista, sustentado na imposição da classificação social da população mundial (QUIJANO, 2009). Logo, a colonialidade do poder se refere à produção de uma noção mundial de humanidade definida a partir de marcadores raciais que passaram a produzir e legitimar relações de poder e de exploração dos povos subalternizados e que se estende desde a colonização até os dias atuais (QUIJANO, 2005). Esses marcadores raciais, pertencentes puramente ao pensamento europeu, permitiu aos colonizadores o enraizamento das diferenças ao plano de identidades passíveis de hierarquização. Tal lógica foi amplamente colaborativa aos sistemas de expropriação das vidas subalternizadas, possibilitando ao colonialismo e capitalismo desenvolverem uma complexa estrutura de pilhagem sócio-racial (QUIJANO, 2009).

A colonialidade refere-se, portanto, a um sistema que embora seja mais recente que a colonização, é ainda mais extensivo e profundo em suas ações exploratórias. Sua capilarizada rede de atuação (poder, conhecimento e ser) se tornou tão vasta durante os mais de 500 anos de história da América a ponto de hoje se constituir como um efetivo modo de ser sociedade. A eficiência da colonialidade reside em sua capacidade de reativar constantemente os valores e sentidos coloniais, expandi-los e administrá-los em diferentes dimensões das sociedades, fazendo com que suas engrenagens de dominação e exploração dos territórios e vidas dos povos subjugados estejam em constante aperfeiçoamento.

Nesse sentido, a colonialidade pode ser imediatamente sublinhada como uma realidade concreta e simbólica em nosso país, em que seu acento mais expressivo reside justamente na estrutura e funcionamento do Estado que, a partir de resquícios coloniais, vêm executando uma velha política de exploração predatória, violenta e intermitente dos espaços dominados, cujo objetivo é a amplificação do poder e riquezas dos grupos hegemônicos. No ínterim dessa razão colonial se inserem as políticas ambientais brasileiras, que mesmo ante a uma moderna legislação preservacionista, não implementou com consistência os dispositivos de proteção ao meio ambiente, o que absolutamente pode ser reconhecido no avanço persistente da devastação dos grandes biomas nacionais. O que se percebe, desse modo, é uma continuação da lógica colonial de exploração dos territórios colonizados.

Historicamente, pode-se observar que, desde o Descobrimento e o estabelecimento dos primeiros colonizadores portugueses, a natureza é objeto de exploração para fins econômicos, a exemplo do comércio internacional do pau-brasil, usado como madeira ou para a extração de seus pigmentos como corantes. Desde aquela fase aos 
dias atuais, ocorrem formas distintas e fases de exploração dos recursos naturais, que propiciam as bases para a legislação ambiental brasileira e sua aplicação na gestão ambiental (CÂMARA, 2013, p. 126).

Embora sejam notáveis as transformações que vêm ocorrendo desde a colonização na legislação ambiental, o que se põem em relevo não é a capacidade discursiva dos governos, de ao menos no âmbito legislativo produzirem um robusto aparato legal de proteção ambiental, mas sim sua resiliente incapacidade de executar os dispositivos legais por ele mesmo elaborados. O que indica que o problema da devastação ambiental no Brasil seja menos uma questão de crença e mais de essência. A manutenção de uma economia agrária centrada em latifúndios, com produção basicamente destinada à exportação ao Norte-Global controlada por uma elite branca e burguesa, a deficitária prestação de serviços oferecidos pelos órgãos ambientais em decorrência do sucateamento de sua infraestrutura e escassez de pessoal, além da ação colaborativa do judiciário, que historicamente vem se mostrando inepto em julgar e condenar os crimes ambientais e aqueles praticados contra ambientalistas, povos indígenas e quilombolas, são indicativos de que a colonialidade não é meramente epistêmica e metafísica, mas uma potência material que age violentamente contra os territórios e povos dominados, além de se encontrar institucionalizada no corpo do Estado que direta ou indiretamente abriga em sua estrutura o chancelamento à depredação do meio ambiente.

Exemplo disso são as políticas ambientais no atual governo. A famosa frase de Salles sobre "passar a boiada", apesar de se referir à pandemia como momento oportuno para mudar a legislação ambiental, vem ocorrendo deliberadamente desde o início da gestão de Bolsonaro em janeiro de 2019, já que "desde que assumiu a pasta, o ministro criou regras que dificultaram a aplicação de multas; transferiu poderes do Ministério do Meio Ambiente para outras pastas; e tentou mudar o entendimento sobre normas como a Lei da Mata Atlântica" (SHALDERS, 2020; BIODIVERSIDAD LA, 2020).

Recentemente foram editadas algumas instruções normativas que visivelmente demonstram o governo atuando por políticas engendradas pela colonialidade. A Instrução Normativa n ${ }^{\circ} 09$ de março de 2020, editada pelo IBAMA, que regulariza propriedades rurais em terras indígenas (IBAMA, 2020), a Instrução Normativa n ${ }^{\circ} 13$ de abril de 2020, editada pelo Ministério da Agricultura, Pesca e Abastecimento (MAPA), que tratou da diminuição da distância entre áreas povoadas e aquelas em que ocorrem pulverização de agrotóxicos (MAPA, 2020), a autorização em outubro de 2020 da pesca em Fernando de Noronha, mesmo com parecer contrário da equipe técnica do Instituto Chico Mendes de Conservação da Biodiversidade (ICMBio), a decisão do Conselho Nacional do Meio Ambiente (Conama) que alterou as resoluções 302 e 303, ambas de 2002, retirando da proteção estrita as áreas 
de restingas e manguezais, abrindo espaço para a ocupação irregular nesses territórios (ANTUNES, 2020). Todos estes atos, proferidos por órgãos de defesa ambiental demonstram de modo inequívoco que a colonialidade não é um mero instrumento, mas fundamento das atuais políticas ambientais, uma vez que operam pelo princípio tradicional do colonialismo, que consiste em explorar irresponsavelmente a terra, seus recursos e seus povos naturais para atendimento das demandas insaciáveis do capitalismo ao mesmo tempo que sugerem uma radical transformação dos órgão de defesa ambiental, que abertamente passam a operar em sentido contrário às suas funções institucionais.

É interessante notar o quanto essas políticas atuam pelo princípio da diferença colonial. Esse termo foi desenvolvido por Walter Mignolo na obra Histórias locais/projetos globais: colonialidade, saberes subalternos e pensamento liminar (2003) e diz respeito ao:

[...] espaço onde emerge a colonialidade do poder. A diferença colonial é o espaço onde as histórias locais que estão inventando e implementando os projetos globais encontram aquelas histórias locais que os recebem; é o espaço onde os projetos globais são forçados a adaptar-se, integrar-se ou onde são adotados, rejeitados ou ignorados. A diferença colonial é, finalmente, o local ao mesmo tempo físico e imaginário onde atua a colonialidade do poder, no confronto de duas espécies de histórias locais visíveis em diferentes espaços e tempos do planeta (MIGNOLO, 2003, p. 10).

A diferença colonial trata das situações conflitivas oriundas do encontro das diferenças, que culmina com o surgimento de dois lados humanos, um habitado por sujeitos com poder e privilégios, e outro, por vidas subalternizadas, ambos os sujeitos determináveis por normas universalizadas pelo pensamento hegemônico (GROSFOGUEL, 2008). A diferença colonial é, segundo o pensamento mignoliano, a fratura discursiva que faz com que aquelas histórias locais dos povos europeus sejam impostas às histórias e projetos locais dos povos americanos, a partir do autorreferenciamento de superioridade europeia que implicou ao Outro o arrefecimento de seus próprios projetos, no silenciamento de suas culturas e na superação de suas próprias narrativas (MIGNOLO, 2003). A diferença colonial permite, desse modo, o surgimento da colonialidade, uma vez que transforma o Outro em um sujeito desarrazoado em seu discurso e negado em sua cosmovisão de mundo (LUGONES, 2014).

Enquanto espaços, concretos e simbólicos, em que duas forças diferentes colidem, a diferença colonial torna-se o elemento fundamental para a produção de políticas centradas na colonialidade do poder, uma vez que é ela quem alimenta a razão colonial de fragmentação e hierarquização das diferenças, produzindo com isso universos paralelos em que são alocados, de um lado, os grupos 
hegemônicos, e de outro, aqueles que carregam as insígnias das raças e gêneros inferiorizados. Nesse sentido, no que concerne às políticas estatais de proteção ao meio ambiente, o que vigora, em termos da diferença colonial é o acirramento das histórias e projetos veiculados pelo Estado, a partir das perspectivas e orientações globais, e aquelas locais desenvolvidas pelos povos indígenas, ribeirinhos, quilombolas e demais minorias que estão vinculadas a terra a partir de cosmologias sistêmicas e holísticas.

O princípio da diferença colonial, nas atuais políticas de meio ambiente, é facilmente observada na atuação do governo de Bolsonaro em que a linguagem colonial se faz explícita e sem nenhum tipo de pudor. Na mesma reunião em que Salles propôs mudanças ao regramento ambiental, o então ministro da educação, Abraham Weintraub disse: "odeio o termo povos indígenas. Odeio este termo. Odeio" (MORAES, 2020). A fala do ministro da educação se encontra alinhavada a uma postura de governo que se sustenta na configuração do Outro não hegemônico como um sujeito miserável, não-humano, um entrave ao desenvolvimento, um verdadeiro inimigo do Estado (FOUCAULT, 1993). O Outro como um inimigo, cinde com as possibilidades dialéticas de diálogo e o circunscreve em perímetros da diferença, do outro lado da margem como preconiza Mignolo. Essa noção da diferença como inimiga norteia de modo fundamental as políticas ambientais, que passam a vigorar não em defesa de seus objetivos legais, mas na proteção dos interesses capitalistas em que se encontra ancorado o extrativismo predatório da terra, de seus recursos e de seus povos.

Segundo dados apresentados no Relatório Violência Contra Povos Indígenas no Brasil - Dados de 2019, produzido pelo Conselho Indigenista Missionário (CIMI), só no primeiro ano do governo de Jair Bolsonaro dobrou o número de invasões e expropriações de terras indígenas (CIMI, 2019). Em 2019 foram registrados um total de 256 casos de invasões, exploração ilegal de recursos e danos ao patrimônio em 151 terras indígenas, de 143 povos, de 23 estados, o que representa um aumento de 135\% a mais do que em 2018. O relatório apresenta ainda um total de 113 assassinatos de indígenas.

Segundo o referido documento, o aumento de queimadas diz respeito a um projeto criminoso que visa "disponibilizar suas terras e os bens comuns nelas contidos aos empresários do agronegócio, da mineração e das madeireiras, dentre outros" (CIMI, 2019, p. 06). Estes ataques aos territórios e aos povos indígenas indicam a manutenção da tradição colonial de usurpação e violência aos povos originários. Tal cenário reflete a pujança da colonialidade do poder no que concerne à violação dos direitos dos povos subalternizados. Não é atoa que o número de invasões aos territórios indígenas tenha aumentado justamente em um governo que tem em seus pronunciamentos demonstrado total 
aversão às minorias, ao mesmo tempo em que sinaliza abertamente seu apreço ao neoliberalismo em sua forma mais voraz.

As comunidades quilombolas também têm sofrido com as políticas ambientais do governo Bolsonaro, desde sua posse houve uma estagnação no reconhecimento fundiário desses territórios. O reflexo da ausência desse tipo de política pública repercute na ampliação da vulnerabilidade dessas comunidades a invasões, despejos e, na desassistência de seguridade social tão fundamental nesse tempo de pandemia. Em 2019 foram expedidos apenas dois títulos para quilombos e em 2020 apenas 05 (CRUZ, 2020). As dificuldades que as comunidades remanescentes de quilombo encontram na atual gestão do governo federal ocorrem prioritariamente dentro dos órgãos cuja incumbência está precisamente no amparo a estas populações. Desde a chegada de Sérgio Camargo à Fundação Cultural Palmares, órgão que emite a certificação de que de fato o território em análise é de natureza quilombola, documento obrigatório para o reconhecimento dessas terras, tais procedimentos foram em sua maioria suspensos.

Tanto os povos indígenas quanto os quilombolas possuem histórica relação de harmonia, sustentabilidade e íntima conexão identitária com a terra, o que faz desses grupos verdadeiros guardiões das áreas de preservação ambiental (CHACPE, 2014). Portanto, o ataque a estes grupos é um ataque a todo sistema ecológico em que estão inseridos, não havendo a menor possibilidade de dissociar dessas ofensas humanitárias à violação dos direitos da natureza e de toda a humanidade.

A política do atual governo federal tem sido a de aplicar a colonialidade do poder de dentro para fora dos órgãos de proteção e defesa dos direitos da natureza e dos povos originários, convertendo essas estruturas estatais em verdadeiras máquinas predatórias, recuperando hoje, mais do que nunca, nosso passado colonial, perseguindo e exterminando minorias, devastando a terra e seus bens e concentrando com maior eloquência a renda em mãos brancas, cristãs e cisheterossexuais. O conjunto substancioso de atos normativos que estão sendo expedidos pelos órgãos de proteção ambiental sugere sua inversão, em que aqueles que deveriam proteger passam a agir pela exposição dos biomas às ações exploratórias do capitalismo em sua forma mais crua e incontida. $\mathrm{O}$ giro colonial promovido pelo governo bolsonarista dentro das instituições de defesa ambiental, consiste na reestruturação desses órgãos a partir da expedição de atos legais que claramente redefinem as funções dos órgãos ambientais.

Diferente de outros governos, que embora tenham sido pouco eficientes em implementar os códigos de defesa ambiental, mas que mantiveram a natureza institucional dos órgãos ambientais, garantindo o debate público e a transparência em torno das questões pertencentes ao meio-ambiente, 
o atual Poder Executivo se destaca pela radical transformação das instituições públicas de proteção ambiental e pelo cerceamento à ampla discussão que a temática merece. Basta lembrar, além do que já foi exposto, que uma das primeiras ações de Jair Bolsonaro, enquanto presidente foi reduzir a composição do Conselho Nacional do Meio Ambiente de 96 representantes para 23, sendo que a participação da sociedade civil foi a mais restringida, o que indica que o encolhimento do Conama foi uma estratégia política de obstrução dos espaços de diálogos sociais em benefício da iniciativa privada, bem como em arquitetar uma infraestrutura institucional propícia para "passar a boiada".

Embora a colonialidade funcione com maior ou menor intensidade na história política do país, atualmente o que se descortina é sua face mais virulenta, agressiva e incontida. Os discursos presidenciais cada vez mais se mostram agressivos e agem intensivamente para a desqualificação das manifestações ecoadas do outro lado da diferença colonial promovidas pela resistência dos povos subalternizados, pela desvalorização da ciência e pela articulação de uma gestão de governo pautada fundamentalmente em Fake News. Os resultados disso refletem na depredação dos biomas nacionais em níveis jamais vistos com impactos socioambientais de difícil mensuração.

O que se tem como efeito imediato é o aprofundamento da diferença colonial em que de um lado grande contingente de vidas locais são tensionadas à miséria e à morte, enquanto de outro, um pequeno grupo formado por identidades eurocêntricas se legitima em privilégios. Recorte evidente disso é a precária assistência prestada pelo governo federal às comunidades quilombolas e aos povos indígenas durante a pandemia de Covid-19 (SENADO FEDERAL, 2020). Enquanto o governo federal negava a gravidade da crise sanitária pelo qual o país passava, fazia ao mesmo tempo aberta defesa ao capital e a sua economia neoliberal. Como resultado, o que se viu foram indígenas, quilombolas, comunidades de periferias e pobres de um modo geral, contando seus mortos enquanto a balança comercial do agronegócio atingia acúmulo jamais visto. Conforme a Confederação da Agricultura e Pecuária do Brasil (CNA), em 2020 o aumento no valor exportado de produtos agropecuários foi 17,9\% em comparação a 2019, e os ganhos em volumes foram de 34,1\% (CNA BRASIL, 2020). Há nesse sentido, uma notória dicotomia produzida pela diferença colonial que mais que sugerir a quem servem as políticas ambientais produzidas no governo Bolsonaro, expõe as vísceras de um sistema de governo pactuado com a elite burguesa brasileira, que por sua história colonial mantém-se latifundiária, sustentada pelo agronegócio, branca, cisheterossexual e cristã.

Enfim, tanto os discursos quanto as políticas executadas pelo governo Bolsonaro dispensam legendas, são coesos em sua essência, pois não se contradizem, são o que são, impiedosos, exploratórios, excludentes e fiéis à colonialidade e se manifestam sem nenhum tipo de acanhamento. 
Seu governo trabalha a olhos nus e não se preocupa em mitigar a opinião pública e de especialistas, pelo contrário, age orientado pela razão extremista sem nenhum espaço ao diálogo, principalmente com os grupos socialmente marginalizados. Sua gestão aprofunda a diferença colonial ampliando o abismo de desigualdades que separam em paralelo as histórias e projetos globais (acentuadamente capitalistas) com aqueles locais em que a defesa da terra é o principal objetivo.

Nesse sentido, é possível configurar a política ambiental do governo Bolsonaro, como políticas da colonialidade que funcionam não para proteção do meio ambiente e dos povos imediatamente ligados aos biomas nacionais, mas para satisfação dos tradicionais grupos legitimados no poder, que hoje, tanto quanto em nosso passado colonial, se sustentam pelo agronegócio, exploração irrestrita da terra e das identidades subalternizadas, aumentando sem limites os seus lucros enquanto uma grande massa padece com a pobreza decorrente do incisivo processo de exclusão a qual é submetida.

A política ambiental adotada na gestão bolsonarista age pela conversão dos órgãos de defesa do meio ambiente em estruturas que operam para satisfação da colonialidade, ou seja, inverte a lógica legal das estruturas institucionais para que elas se desviem de seu objetivo fundamental que é a preservação dos biomas nacionais, e possam legitimar os interesses dos grupos hegemônicos, servido ao capital e não a biodiversidade em si. Nunca se viu algo tão explícito e profundo quanto o que se observa nessa gestão do executivo federal, o que não inibe a concepção de que essa talvez seja a mais potente e violenta manifestação das políticas da colonialidade de poder de nossa história.

Por fim, as políticas da colonialidade voltadas ao meio ambiente estão inseridas em uma pauta governista que atua de dentro para fora, reestruturando órgãos e subvertendo a lógica preservacionista das instituições públicas. Sua ação se dá pela edição de atos legais que concretizam o capital e os grupos hegemônicos como prioridade e não a natureza.

\section{O BEM VIVER: A POSSIBILIDADE DE NOVOS CAMINHOS}

As atuais políticas governamentais têm como objetivo o ideal de desenvolvimento a qualquer custo, em consequência o extrativismo é visto como uma necessidade elementar para alavancar o crescimento nacional a outro patamar. A noção de natureza/mercadoria criou uma ideia de superioridade do humano em relação à natureza, que leva diretamente à uma dicotomia humano/natureza que não se evidencia na realidade. A interpretação ocidental de um meio ambiente visto como algo externo e não em relação direta conosco, contribui com essa concepção (ACOSTA, 
2019). É importante evidenciar que as políticas do atual governo se pautam numa concepção antropocêntrica, centrada na dominação e exploração dos recursos naturais, assim como na potencialização da destruição de povos originários.

Diante dessa lógica antropocêntrica de dominação, é urgente a elaboração de um novo tipo de ética que inter-relacione o ser humano e a natureza em sentido harmônico. Nesse sentido, O Bem Viver (Sumak Kawsay na língua Kichwa) traz possibilidade de contestar toda essa realidade predatória, para pensarmos na construção de um mundo novo pautado no respeito à natureza e à dignidade humana. O Bem Viver é um conjunto de saberes em construção que se originam - tendo várias denominações - nos povos originários latino-americanos: Kichwa, Aimarás, Guaranis etc., cada povo em sua particularidade contribui com a construção do Bem Viver, que muito mais do que um saber unitário e dogmático, é plural e dinâmico em sua construção (ACOSTA, 2019).

O Bem viver está pautado numa prática ética que se distancia da lógica antropocêntrica, subvertendo a noção de desenvolvimento capitalista através de cosmovisões territorializadas e comunitárias, que propõem relações harmônicas não capitalistas, o que podemos denominar como uma ética biocêntrica, comunitária, não individualista, que se sustenta na pluralidade e diversidade dos povos. Para compreendê-lo é necessário desaprender e reaprender o aprendido, se submetendo a um intenso processo de descolonização do saber (ACOSTA \& BRAND, 2019).

A política ambiental predatória do governo Bolsonaro é a manifestação de uma lógica de mercado que tem no ideal de desenvolvimento, através de produtos primários, seu ponto de referência. O "passar a boiada" envolve justamente a possibilidade de flexibilizar leis ambientais, beneficiando em sua maioria o agronegócio, responsável direto pela degradação ambiental e à violência aos povos originários. É importante criar novas saídas, que como pontua Acosta (2019) questionem a própria ideia de desenvolvimento, não o desenvolvimento como os ditos desenvolvimentos “sustentáveis" no capitalismo, mas sim procurar alternativas ao próprio desenvolvimento, alternativas essas que podem ter no Bem Viver uma bússola de grande serventia para guiar novos caminhos.

Dentre as diversas discussões de políticas ambientais que surgiram nos últimos anos e que ganham cada vez mais espaço, encontram-se atreladas as referentes ao Bem Viver, em que o núcleo consiste no reconhecimento dos direitos da Natureza, que possivelmente é uma das mudanças mais drásticas na forma como nos relacionamos com o meio ambiente, pois envolve o admissão da Natureza como sujeito de direito, o que implica a necessidade de uma nova forma de relacionamento com a mesma, saindo de cena a natureza/mercadoria que deve ter seus recursos naturais explorados ao máximo, entrando em cena uma relação que entenda os limites naturais dos ecossistemas, 
consequentemente esses ecossistemas devem ser preservados e seus habitantes originários devem ser protegidos (GUDYNAS, 2020).

O primeiro país no mundo que instituiu os direitos da Natureza de forma legal foi o Equador no ano de 2008, estabelecendo na Constituição do país a Natureza como sujeito de direito, tendo como alguns pontos importantes: seu direito à preservação, restauração, proteção e ao o direito de não ser mercantilizada, sendo permitidas atividades comunitárias que tenham como base relações não predatórias pautadas no Bem Viver. Com certeza essa implementação foi pioneira, que apesar das muitas limitações práticas, pode servir de exemplo para outros países (MARTÍNEZ, 2017). Nesse sentido, a lógica de desenvolvimento imposta pelo capitalismo é insustentável ecologicamente, sendo necessária uma ruptura com a lógica predatória de mercado para a construção de uma ética biocêntrica, o estabelecimento dos direitos da Natureza é um avanço muito importante nesse objetivo (GUDYNAS, 2020).

Apesar de alguns avanços ocorridos nos ditos governos "progressistas" de Lula e Dilma, a ideia de desenvolvimento vinculada ao crescimento econômico jamais foi contestada, pelo contrário, aumentou nesse período a dependência de exportação de commodities para o mercado mundial, o que fez avançar o agronegócio em zonas de reservas naturais, além disso, não podemos esquecer de um dos maiores crimes ambientais deste século que foi a construção da usina de Belo Monte. Hoje o extrativismo é algo inquestionável no imaginário social, todavia, a promessa de crescimento nunca é alcançada, a dependência de exportação de matérias primas, herança de nosso passado colonial, cria um ciclo vicioso de pobreza e degradação ambiental (SVAMPA, 2019). O atual governo avança nessa lógica de destruição, com o desmonte de políticas ambientais apoiado por grandes grupos relacionados ao agronegócio.

Temos com o ministro Ricardo Salles uma total fragilização do Ministério do Meio Ambiente, em que é manifesto a intenção de rever as unidades de conservação do país, sendo este um tópico muito comentado por Bolsonaro ainda no período de campanha presidencial (SCANTIMBURGO, 2018). As agendas de desmontes de políticas de proteção indígena, quilombola e ambiental, juntamente com o sucateamento e militarização de órgãos responsáveis pela fiscalização, demarcação e proteção ambiental como o INCRA, FUNAI e IBAMA, demonstram sua visão extrativista em relação direta com o agronegócio no país (SAUER; LEITE; TUBINO, 2020). Diante desse cenário, é importante construir coletivamente possibilidades que possam criar novos caminhos para esse atual labirinto que aparenta ser sem saída, assim, o fortalecimento do sentido comunitário junto ao debate do Bem Viver é um caminho possível, que fortalece os Direitos Humanos e os direitos da Natureza. 
O Bem Viver como um fundamento sociopolítico para as nações se insere naquilo que Mignolo chama de pensamento de fronteira. Esse pensamento não é a negação da modernidade tal como ela é, mas uma resposta aos dilemas por ela nutridos. Trata-se de uma resposta epistêmica dos subalternos ao projeto eurocêntrico que se fundamenta nas assimetrias das raças, na subjugação de identidades não eurocêntricas e no projeto de desenvolvimento estruturado pelo predatismo ambiental (GROSFOGUEL, 2008).

Aquilo que o pensamento de fronteira produz é uma redefinição/subsunção da cidadania e da democracia, dos direitos humanos, da humanidade e das relações económicas para lá das definições impostas pela modernidade europeia. O pensamento de fronteira não é um fundamentalismo antimoderno. É uma resposta transmoderna descolonial do subalterno perante a modernidade eurocêntrica (GROSFOGUEL, 2008, p. 138).

Nesse ponto de vista, o pensamento fronteiriço nos permite pensar as atuais políticas no Brasil, em especial as relacionadas ao meio ambiente, uma vez que tais saberes, ao emergirem dos olhares daqueles que foram transformados nas periferias do mundo e ocultados pela violência colonial guardam saberes ancestrais em que a terra e a natureza não são produtos, mas identidades, organismos, sistemas fundamentais para o ordenamento da vida (DUSSEL, 2012).

Essa razão subalterna que nasce das periferias em que foram alocadas as identidades ameríndias e afro-americanas surge de modo crítico a partir de cosmovisões que estão entretecidas em histórias milenares de cuidado e proteção ao meio ambiente. Sua potência consiste justamente nas experiências concretas e simbólicas de povos que vêm desenvolvendo desde seu passado ancestral um tipo de relação com a natureza que cinde totalmente com a lógica exploratória difundida pelo capitalismo. Esses povos nutrem culturas, saberes que se descortinam para toda a humanidade como possibilidade emergente de superação da crise humanitária em que nos encontramos atolados. Recuperar o olhar subalterno é dar ao mundo possibilidades de crescimento integrado e sustentável que a todos foi negado desde a fundação da modernidade como uma verdade global. Nesse sentido, o pensamento de fronteira do Bem Viver é a chance de não apenas o Sul-Global se tornar livre e são, mas de liberdade e cura a todo o planeta, em especial ao seu algoz.

A ruptura epistemológica proposta pelo Bem Viver, nascida e alimentada nos solos colonizados do Sul-Global se desenvolve da própria luta do colonizado, o desenvolvimento de saberes dos subalternos emerge da contestação à interpretação ocidental, até então hegemônica do conhecimento e, sobretudo, é uma contestação radical às dicotomias humana e ambiental promovidas, disseminadas e administradas pelos colonizadores. Frantz Fanon (1968) em seu livro Os condenados 
da terra, reivindicava o direito do colonizado de se utilizar de todos os meios possíveis para combater a violência ontológica do colonizador. Nisso, há necessidade da construção de um saber e uma organização política dos povos oprimidos que torne possível a superação do medo da liberdade do jugo colonial. É importante pensar nesse medo como uma construção político-ideológica que transpassa as diversas sociedades do Sul-global. A superação do chamado fatalismo latino-americano demanda uma tomada de consciência frente a realidade de opressão e um rompimento com o medo da emancipação libertadora ao colonialismo (BARÓ, 1998).

A construção de uma sociedade "sujeito de si mesmo", que deve se fazer no combate a toda forma de opressão através de uma prática concreta de construção de autonomia social tem no campo político o seu maior desafio ideológico (FREIRE, 2014). Aqui cabe resgatar os termos potentia e potestas em seus sentidos elaborados por Dussel. Potentia está diretamente vinculada ao poder à comunidade, está sendo a última instância do político, seria toda a potencialidade de germinação de uma construção política social, e potestas é a manifestação concreta dessa germinação, através da organização e ação política (DUSSEL, 2007). Nessa perspectiva, o fazer político frente a governos opressores sociais e destruidores de biomas como é o caso do atual governo, deve-se pautar na potência criadora que vem do próprio povo como possibilidade da construção de novos caminhos, potências que criem "porteiras" que impeçam o "passar da boiada".

O debate atual sobre pós-extrativismo se tornou um dos principais aliados para a criação de uma sociedade do Bem Viver. Acosta \& Brand (2019) pontuam que a concepção de pós-extrativismo surge no ventre da América Latina, transpassada por seus conflitos e contradições, pensado como uma saída para a degradação ambiental, tem como como ponto fundamental o entendimento de que os recursos naturais são finitos, e se continuarmos nessa lógica destrutiva, caminharemos para a extinção da própria espécie humana. Assim, é necessário repensarmos nossa relação com os recursos naturais, além disso, urgente uma redução drástica do extrativismo, o que envolve uma ruptura com a lógica extrativista de mercado, pensando em alternativas renováveis que favoreçam os direitos da Natureza e da coletividade.

\section{CONSIDERAÇÕES FINAIS}

Sem empatia, sem embasamento científico, às escondidas do povo e quando possível da imprensa, as ações governamentais bolsonaristas anunciam um colapso socioambiental (SCANTIMBURGO, 2018; BIODIVERSIDAD LA, 2020). Os discursos e os atos normativos 
instituídos pelo governo de Jair Bolsonaro tratam o meio ambiente como um entrave ao suposto desenvolvimento pleiteado por essa gestão. Nessa perspectiva as decisões/ações têm sido de extermínio a tudo que possa barrar a passagem da boiada (SCANTIMBURGO, 2018). Como na hegemonia eurocêntrica, a política colonizadora impõe a qualquer custo suas vontades, ainda que isto implique no extermínio de sujeitos vistos como "não-humanos" e, consequentemente destituídos de quaisquer direitos (DUSSEL, 2012).

A ideologia desenvolvimentista predatória ganha cada vez mais potência com o desmonte das políticas ambientais perpetradas pelo atual governo. Nesse momento nebuloso, podemos aprender com os saberes ancestrais dos povos da floresta. Os Yanomami, por exemplo, podem nos ensinar muito sobre a relação humano/floresta e os perigos do extrativismo desenfreado, como na mitologia da queda do céu, que faz alusão ao mito do fim da primeira humanidade, que pode vir a acontecer novamente se o atual descaso com a natureza prosseguir (KOPENAWA \& ALBERT, 2019).

Faz-se necessário descolonizar o imaginário para além de reivindicações institucionais, que dependem do Estado. O governo precisa governar para o povo ouvindo suas necessidades e validando seus saberes. O Bem Viver desponta como um caminho possível e urgente de diálogo coletivo entre cidade, campo e floresta. O debate sobre direitos da Natureza, pós-extrativismo, devem ser vinculados ao ideal de uma sociedade do Bem Viver, que leve em conta os saberes ancestrais, absorvendo também o que há de melhor na modernidade para a construção de um mundo novo. Somente assim, podemos compor outros sentidos de vida que superem a lógica de extermínio, não apenas do atual governo, mas também do próprio sistema capitalista.

\section{REFERÊNCIAS}

ACOSTA, Alberto. O bem viver: uma oportunidade para imaginar outros mundos. São Paulo: Elefante, 2019.

ACOSTA, Alberto \& BRAND, Ulrich. Pós-extrativismo e decrescimento: saídas do labirinto capitalista. São Paulo: Elefante, 2019.

ANTUNES, Paulo Bessa. Legal. Revogação das Resoluções no 302 e 303/ 2002 do Conselho Nacional do Meio Ambiente. Ambiente Legal, São Paulo, 30 de set. de 2020. Disponível em: http://www.ambientelegal.com.br/revogacao-das-resolucoes-no-302-e-303-2002-do-conselhonacional-do-meio-ambiente/. Acesso em: 20 de jan. de 2021.

ARAGÃO, Luiz; SILVA JUNIOR, Celson; ANDERSON, Liana. O desafio do Brasil para conter o desmatamento e as queimadas na Amazônia durante a pandemia por COVID-19 em 2020: implicações ambientais, sociais e sua governança. São José dos Campos, 2020. 34p. SEI/INPE: 01340.004481/2020-96/5543324. Doi:10.13140/RG.2.2.17256.49921. Acesso em 12 de jul. 2021 
CÂMARA. INPE confirma aumento de quase 200\% em queimadas no Pantanal entre 2019 e 2020. Câmara dos Deputados, Brasília, 30 de set. de 2020. Disponível em: https://www.camara.leg.br/noticias/696913-inpe-confirma-aumento-de-quase-200-em-queimadasno-pantanal-entre-2019-e-2020/. Acesso em: 22 de jan. de 2021.

CÂMARA, João. Governança ambiental no Brasil: ecos do passado. Revista de Sociologia Política, v. 21, n. 46, p. 125-146, 2013. Disponível em: https://www.scielo.br/pdf/rsocp/v21n46/08.pdf. Acesso em 28 de jan. de 2021.

CHACPE. Juliana. Territórios quilombolas e unidades de conservação de proteção integral: desafios da conciliação na Administração Federal. Dissertação (Mestrado em Desenvolvimento Sustentável) - Universidade de Brasília. Brasília, 2014. Disponível em: https://core.ac.uk/download/pdf/33548311.pdf. Acesso em: 20 de jan. de 2021.

CNA. Balança comercial do Agronegócio Brasileiro. CNA, Brasília, 2020. Disponível em: https://www.cnabrasil.org.br/boletins/balanca-comercial-maio-2020. Acesso em: 28 de jan. de 2021.

BIODIVERSIDAD LA. Cronologia de um desastre anunciado: ações do Governo Bolsonaro para desmontar as políticas de Meio Ambiente no Brasil. BioDiversidad LA, Brasil, 24 de set. 2020. Disponível em: http://www.biodiversidadla.org/Documentos/Cronologia-de-um-desastre-anunciadoacoes-do-Governo-Bolsonaro-para-desmontar-as-politicas-de-Meio-Ambiente-no-Brasil. $\quad 2020$. Acesso em: 19 de jan. de 2021.

CRUZ, Márcia. Paralisação de titulações por Bolsonaro dificulta combate à Covid-19 nos quilombos. De Olho nos Ruralistas, 16 de jul. de 2020. Disponível em: https://deolhonosruralistas.com.br/2020/07/16/paralisacao-de-titulacoes-por-bolsonaro-dificultacombate-a-covid-19-nos-quilombos/. Acesso em: 28 de jan. de 2021.

DUSSEL, Enrique. 20 teses de política. São Paulo: Expressão Popular, 2007.

DUSSEL, Emrique. Para um diálogo inter-filosófico, Sul-Sul. Revista Filosofazer, n. 41, p. 11-30, 2012. Disponível em: https://enriquedussel.com/txt/Textos_Articulos/444.2013_port.pdf. Acesso em: 20 de jan. de 2021.

FANON, Frantz. Os condenados da terra. Rio de Janeiro: Civilização Brasileira, 1968.

FOUCAULT, Michel. Genealogia del racismo. Buenos Aires: Altamira, 1993.

FREIRE, Paulo. Educação como prática da liberdade. Rio de Janeiro: Paz e Terra, 2014.

GROSFOGUEL, Rámon. Para descolonizar os estudos de economia política e os estudos póscoloniais: transmodernidade, pensamento de fronteira e colonialidade global. Revista Crítica de Ciências Sociais, v. 80, 2008, p, 115-147. doi: https://doi.org/10.4000/rccs.697. Acesso em 23 de jan. de 2021.

GUDYNAS, Eduardo. Direitos da natureza: ética biocêntrica e políticas ambientais. São Paulo: Elefante, 2020. 
IBAMA. Instrução Normativa ${ }^{\circ}$ 09, de 20 de março de 2020. Brasília: Diário Oficial da União: seção 1, Brasília, DF, edição 56, p.106, 23 de mai. de 2020. Disponível em: https://www.in.gov.br/en/web/dou/-/instrucao-normativa-n-9-de-20-de-marco-de-2020-249243190.

Acesso em 20 de jan. de 2021.

KOPENAWA, Davi. \& ALBERT, Bruce. A queda do céu: palavras de um xamã yanomami. São Paulo: Companhia das Letras, 2019.

LUGONES, Maria. Rumo a um feminismo descolonial. Florianópolis: Revista Estudos Feministas, v. 22, n. 03, 2014, p. 935-952. Disponível em: https://periodicos.ufsc.br/index.php/ref/article/view/36755/28577. Acesso em: 18 de jan. de 2021.

MAPA. Instrução Normativa $n^{\circ} 13$, de 08 de abril de 2020. Dispõe sobre a aplicação de fungicidas e óleo mineral com uso de aeronaves agrícolas na cultura da banana. Diário Oficial da União: seção 01, Brasília, DF, edição 69, p. 11, 09 de abr. de 2020. Disponível em: https://www.in.gov.br/en/web/dou/-/instrucao-normativa-n-13-de-8-de-abril-de-2020-251908947.

Acesso em 28 de jan. de 2021.

MARTIN-BARÓ, Ignacio. Psicología de la liberación. Madrid: Trotta, 1998.

MARTÍNEZ, Esperanza. Direitos da natureza: um balanço nos dez anos de seu reconhecimento constitucional no Equador. Montevidéu. Boletim Mensal do Movimento Mundial Pelas Florestas, v. 234, p. 47-50, 2017. Disponível em: https://wrm.org.uy/pt/files/2017/11/Boletin234_PO.pdf. Acesso em: 28 de jan. de 2021.

MIGNOLO, Walter. Histórias locais/projetos globais: colonialidade, saberes subalternos e pensamento liminar. Belo Horizonte: UFMG, 2003.

G1. Ministro do Meio Ambiente defende passar "a boiada" e "mudar" regras enquanto atenção da mídia está voltada para a Covid-19. G1, Brasília, 22 de mai. de 2020. Disponível em: https://g1.globo.com/politica/noticia/2020/05/22/ministro-do-meio-ambiente-defende-passar-aboiada-e-mudar-regramento-e-simplificar-normas.ghtml. Acesso em: 20 de jan. de 2021.

MORAES, Renan. Weintraub atualiza uma compreensão antiquada de "povo brasileiro". HH Magazine, 27 de mai. de 2020. Disponível em: https://hhmagazine.com.br/weintraub-atualiza-umacompreensao-antiquada-de-povo-brasileiro/. Acesso em: 04 de fev. de 2021.

OBSERVATÓRIO DO CLIMA. "Passando a boiada”: o segundo ano de desmonte ambiental sob Jair Bolsonaro. Observatório do Clima, 22 de jan. de 2021. Disponível em <http://www.oc.eco.br/passando-boiada-o-segundo-ano-de-desmonte-ambiental-sob-jairbolsonaro/>. Acesso em: 28 de jan. de 2021.

QUIJANO, Anibal. Colonialidade do poder e classificação social. In: SANTOS, B. DE S.; MENESES, M. P. (Org.). Epistemologias do sul. Coimbra: Almediana, 2009. p. 73-117.

QUIJANO, Anibal. Colonialidade do poder, eurocentrismo e América Latina. In: QUIJANO, A. A colonialidade do saber: eurocentrismo e ciências sociais, perspectivas latino-americanas. Buenos Aires: CLACSO, 2005. p. 117-142. 
SAUER, Sérgio; LEITE, Acácio; TUBINO, Nílton. Agenda política da terra no governo Bolsonaro. Revista da ANPEGE, v. 16, n. 29, p. 283-316, 2020. Disponível em: https://ojs.ufgd.edu.br/index.php/anpege/article/view/12518. Acesso em: 28 de jan. de 2021.

SCANTIMBURGO, André. $O$ desmonte da agenda ambiental no governo Bolsonaro. Perspectivas: Revista de Ciências Sociais, v. 52, 2018 . Disponível em: <https://periodicos.fclar.unesp.br/perspectivas/article/view/13235〉. Acesso em: 28 de jan. de 2021.

SHALDERS, André. Passando a boiada: 5 momentos nos quais Ricardo Salles afrouxou regras ambientais. BBC News, Brasília, 01 de out. de 2020 . Disponível em: https://www.bbc.com/portuguese/brasil-54364652. Acesso em: 21 de jan. de 2021.

SVAMPA, Maristella. As fronteiras do neoextrativismo na América Latina: conflitos socioambientais, giro ecoterritorial e novas dependências. São Paulo: Elefante, 2019.

CIMI. Violência contra os povos indígenas no Brasil. CIMI. Disponível em: https://cimi.org.br/wpcontent/uploads/2020/10/relatorio-violencia-contra-os-povos-indigenas-brasil-2019-cimi.pdf. Acesso em: 24 de jan. de 2021.

WESTIN, Ricardo. Atingidos pela pandemia, indígenas contam seus mortos e acusam governo de omissão. Senado Federal, Brasília, 07 de ago. de 2020. Disponível em: 